First Peoples Child \& Family Review

An Interdisciplinary Journal Honouring the Voices, Perspectives, and Knowledges of

First Peoples through Research, Critical Analyses, Stories, Standpoints and Media

Reviews

\title{
Knowledge Translation in a Community-Based Study of the Relations Among Violence Exposure, Post-traumatic Stress and Alcohol Misuse in Mi'kmaq Youth
}

\author{
Marc Zahradnik, Sherry Stewart, Doreen Stevens and Christine Wekerle
}

Volume 4, Number 2, 2009

URI: https://id.erudit.org/iderudit/1069334ar

DOI: https://doi.org/10.7202/1069334ar

See table of contents

Publisher(s)

First Nations Child and Family Caring Society of Canada

ISSN

1708-489X (print)

2293-6610 (digital)

Explore this journal

Cite this article

Zahradnik, M., Stewart, S., Stevens, D. \& Wekerle, C. (2009). Knowledge Translation in a Community-Based Study of the Relations Among Violence Exposure, Post-traumatic Stress and Alcohol Misuse in Mi'kmaq Youth. First Peoples Child \& Family Review, 4(2), 106-117. https://doi.org/10.7202/1069334ar

\section{Article abstract}

In 2004, our research group was invited to continue a research partnership with a Nova Scotian Mi'kmaq community that was concerned about the causes of and interventions for adolescent alcohol misuse in their community. While our previous collaborative research focused on reducing adolescent alcohol misuse by targeting motivations for drinking that were personality specific (see Mushquash, Comeau, \& Stweart, 2007), the more recent collaboration sought to investigate the possible relationship between exposure to violence, post-traumatic stress, and alcohol misuse. The present paper outlines the steps involved in gaining community consent, the plan for results sharing, the tangible benefits to the community that have been documented, and future directions and lessons learned. The paper will demonstrate how the principles of Knowledge Translation (CIHR, 2006) provide a framework for this process.
Copyright @ Marc Zahradnik, Sherry Stewart, Doreen Stevens, Christine Wekerle, 2009
This document is protected by copyright law. Use of the services of Erudit (including reproduction) is subject to its terms and conditions, which can be viewed online.

https://apropos.erudit.org/en/users/policy-on-use/ 


\section{Ifilesit Peoples Child \& Samily Review}

An Interdisciplinary Journal Honoring the Voices, Perspectives and Knowledges of First Peoples through Research, Critical Analyses, Stories, Standpoints and Media Reviews

\section{Knowledge Translation in a Community-Based Study of the Relations Among Violence Exposure, Post-traumatic Stress, and Alcohol Misuse in Mi'kmaq youth}

\author{
Marc Zahradnika , Sherry Stewart ${ }^{\mathrm{b}}$, Doreen S \\ ${ }^{a}$ Department of Psychology, Dalhousie Univeristy, Halifax, NS, \\ Canada \\ ${ }^{\mathrm{b}}$ Department of Psychiatry, Dalhousie University, Halifax, NS, \\ Canada \\ c Department of Psychology, Mount Saint Vincent University, \\ Halifax, NS, Canada \\ ${ }^{d}$ Faculty of Education, Department of Psychology, University of \\ Western Ontario, London, ON, Canada
}

\section{Introduction}

Indigenous peoples world-wide have been confronted with a global economy that would appear to care little for their autonomy or sense of cultural identity (Kirmayer, Bass, \& Tait, 2000). In many cases, such rapid change creates a sense of cultural discontinuity, which has been linked in many communities to high rates of problems with depression, alcoholism, suicide, and violence (Kirmayer et al., 2000). The most profound impacts have been observed among indigenous youth (Kirmayer et al., 2000). Unfortunately, such problems exist in many Canadian Aboriginal communities today. Many of the problems that Canadian Aboriginal communities must struggle with have at their origin a colonial past of conquest and subsequent pattern of paternalistic and aggressive attempts at assimilation, culminating in such policies as those that lead to the residential school system (see Armitage, 1995; Indian and Northern Affairs,

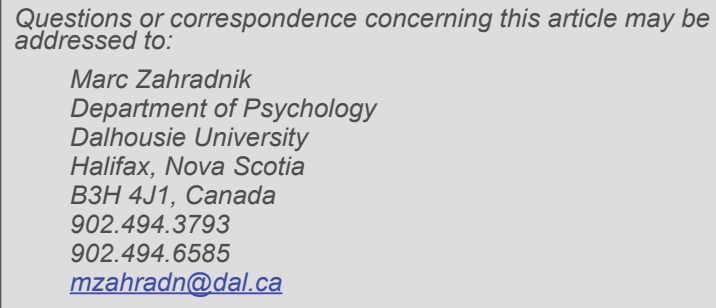

\begin{abstract}
In 2004, our research group was invited to continue a research partnership with a Nova Scotian Mi'kmaq community that was concerned about the causes of and interventions for adolescent alcohol misuse in their community. While our previous collaborative research focused on reducing adolescent alcohol misuse by targeting motivations for drinking that were personality specific (see Mushquash, Comeau, \& Stewart, 2007), the more recent collaboration sought to investigate the possible relationship between exposure to violence, post-traumatic stress, and alcohol misuse. The present paper outlines the steps involved in gaining community consent, the plan for results sharing, the tangible benefits to the community that have been documented, and future directions and lessons learned. The paper will demonstrate how the principles of Knowledge Translation (CIHR, 2006) provide a framework for this process.
\end{abstract}

1996; Knockwood, 1992; Miller, 1996). Sadly, 20-30 percent of Canada's Aboriginal Peoples (approximately $100,000)$ attended residential schools (Thomas \& Bellefeuille, 2006), and many of those exposed to the residential school system were abused and/or neglected. The residential school system left many of its "students" alienated from two cultures, without healthy role models for parenting (Quinn, 2007). Subsequently, many lacked the necessary knowledge and skills to provide healthy parenting to their own children (Bennett \& Blackstock, 2002; Grant, 1996). And so the legacy of colonization, largely by way of the residential school system, left in its wake a process of intergenerational or multigenerational trauma (Gagne, 1998; Wesley-Esquimaux \& Smolewski, 2004), in which many of the problems faced by aboriginal communities today are cyclically perpetuated. In Canada, Aboriginal children and youth are over twice as likely to be investigated, to be reported for neglect, and placed 


\begin{abstract}
Author Notes:
This project was supported in part by a Canadian Institutes of Health Research New Emerging Team (CIHR NET) grant held by Drs. Christine Wekerle and Sherry Stewart, as well as an Atlantic Aboriginal Health Research Program (AAHRP), a CIHR-Institute of Aboriginal Peoples Health (CIHR-IAPH) funded Aboriginal Capacity and Developmental Research Environment (ACADRE) research allowance held by Marc Zahradnik. Mr. Zahradnik was also funded by an AAHRP graduate student award, and is presently funded by a Nova Scotia Health Research Foundation (NSHRF) graduate student award. Dr. Stewart is supported through a CIHR Investigator Award and a Killam Research Professorship. Dr. Wekerle is supported through an Ontario Women's Health Council/CIHR Mid-Career Award.
\end{abstract}

in foster care than non-Aboriginal groups (First Nations Child \& Family Caring Society of Canada, 2005).

It is with this understanding of the larger historical context of Canada's First People that we began a community-based collaborative project with a Nova Scotian Mi'kmaq community that sought to understand how such things as violence, depression, anxiety, and addictions fit together in the lives of their youth today. While we recognize the historical and cultural roots to maltreatment and substance misuse problems in some Aboriginal communities, our study was not designed to test the contribution of these historical factors (Zahradnik, Stevens, Stewart, Comeau, Wekerle, \& Mushquash, 2007a). Rather, we sought to examine whether or not there was a pathway from exposure to violence through the mental health consequences of such a trauma (e.g., post-traumatic stress or depression) through to alcohol misuse, in a sample of school-attending adolescents.

The results of our research made a strong case for how certain aspects of post-traumatic stress disorder (PTSD) helped make sense of the exposure to violence alcohol misuse relationship. PTSD is an anxiety disorder that can sometimes follow from exposure to a traumatic event, like exposure to interpersonal violence (APA, 1994). PTSD manifests itself by way of three symptom clusters: re-experiencing symptoms, hyper-arousal, and avoidance and numbing ${ }^{1}$. Our study demonstrated that the symptom cluster of hyper-arousal served as a mediating factor (i.e., acted as an explanatory bridge) in the relationship between exposure to violence and subsequent alcohol problems (Zahradnik, Stewart, Stevens, Wekerle, $\&$ Mushquash, 2007b). These findings are consistent with the self-medication hypothesis (Chilcoat \& Breslau, 1998; De Bellis, 2002; Stewart, 1996), in which individuals

\footnotetext{
1 The DSM-IV-TR (APA, 2000) defines PTSD as an illness that is precipitated by exposure to a traumatic event (experiencing or witnessing the threat of death or the physical integrity of a person) in which the individual responds to the traumatic event with a sense of fear, helplessness, or horror, and within a month of the event develops symptoms from the following three symptom clusters: 1) re-experiencing (e.g., nightmares), 2) hyper-arousal (e.g., hypervigilance), and 3) avoidance (e.g., avoiding people or places associated with the trauma)and emotional numbing (e.g., sense of a foreshortened future).
}

use alcohol and/or drugs to alleviate the PTSD hyperarousal symptoms that resulted from an earlier exposure to a trauma. Both the results of the study and our recommendations have been communicated back to the community. Presently, we are working together with the community to facilitate the process of acting upon the recommendations.

The purpose of the present paper is to demonstrate to the reader how our ongoing, collaborative, community research study (see also Zahradnik et al., 2007a) is congruent with what the Canadian Institutes of Health Research call integrated knowledge translation (KT) (CIHR, 2008a). Integrated KT is an approach to conducting research by which both researchers and research-users work together to shape the research process (CIHR, 2008a). The steps involved in our ongoing KT dissemination plan can be divided as follows: 1) community consent; 2) sharing of results; 3) tangible benefits and documented responses; and 4) future directions and lessons learned. The heading names designated for each step should be conceived of as part of an organizational heuristic for the purpose of this paper. This is because each step (e.g., community consent) often contains within it multiple steps that taken together are consistent with CIHR's six opportunities for KT within the research cycle 2 (CIHR, 2008b). We describe each of our steps in turn, below.

\section{Community Consent}

As the community we have been working with is a self-governing one, the issue as to what type of knowledge should be researched, let alone translated, had to be decided upon by various levels of the community. Ultimately, the band-appointed directors of both the board of education and the board of health had to bestow

\footnotetext{
2 These six opportunities are as follows: 1) defining research questions and methodologies; 2) conducting research (as in the case of participatory research); 3) publish research findings in plain language and accessible formats; 4) placing research findings into the context of other knowledge and socio-political norms; 5) making decisions and taking action informed by research findings; and 6) influencing subsequent rounds of research, based on the impacts of knowledge use.
} 
their approval upon the final iteration of the project, but this final version evolved gradually as a function of community input. To follow is a brief account of how our initial contact with the community led to the identification of two topics about which the community wished to become more knowledgeable. Specifically, these two topics were (1) childhood exposure to violence-in the form of physical, sexual, emotional abuse, and witnessing domestic violence - and (2) post-traumatic stress reactions and PTSD (for a full description, see Zahradnik et al., 2007a).

Our research team was first invited to work with this community back in 2002, when the community wanted to discuss ways of improving the success of their efforts to tackle teen alcohol misuse in their community. That invitation eventually resulted in the participation of both the community youth and the school staff in the development of a culturally relevant early intervention program for alcohol misuse, entitled 'Nemi'simk, Seeing Oneself" (see Comeau et al., 2005), which was shown to be effective in reducing rates of drinking, binge drinking, and levels of alcohol problems in high personality risk youth (see Mushquash et al., 2007). From the qualitative phase of the "Nemi'simk" project, some of the youth identified exposure to violence as being connected to their motivations for drinking. As it turned out, exposure to violence was becoming a topic of concern to some of the community service providers as well, based on their experiences in working with youth in this community.

In the fall of 2005, a school guidance counselor involved with the "Nemi'simk" project spoke to our group in the interest of collaboration and linked the themes of violence expressed by some of the youths to her own observation of the growing number of disclosures of child abuse in her community. This led our group to reflect on what has been written about the relationship between childhood maltreatment and alcohol misuse. In short, interpersonal violence increases the risk for the development of PTSD (Brewin, Andrews, \& Valentine, 2000; Wekerle \& Wall, 2002). Not only is the development of PTSD linked to subsequent alcohol misuse (Kilpatrick et al., 2003; Stewart, 1996; Wekerle \& Wall, 2002), but sexual assault, physical assault, and witnessing violence are all variables that increase the risk of developing co-morbid (i.e., concurrent) PTSD and alcohol abuse/dependence. Furthermore, some researchers have argued that the relationship between these three variables (maltreatment, PTSD, and alcohol misuse) is best explained by the self-medication hypothesis (Chilcoat \& Breslau, 1998; DeBellis, 2002; Stewart, 1996), in which individuals use substances to temporarily find relief from their anxiety symptoms (e.g., hyper arousal). Continued self-medication may then lead to what some researchers have described as a mutual maintenance model (Jacobsen, Southwick, \& Kosten, 2001; Stewart $\&$ Conrod, 2008) in which the physiological arousal associated with substance (e.g., alcohol) withdrawal symptoms exacerbates hyper-arousal symptoms leading to the long-term maintenance of the co-morbid PTSD and alcohol disorder.

Given these well-documented, empirical links between variables, and the perceived community relevance, we therefore thought that a study that examined how PTSD symptoms might bridge (i.e., mediate) the relationship between childhood exposure to violence ${ }^{3}$ and subsequent problems with alcohol would be well received by the community. We immediately shared this idea with the guidance counselor, which lead to a decision to bring this idea before the director of education and other community stakeholders. The guidance counselor was invited to join the research team, and she assumed the dual roles of both a co-investigator and community champion. As credible advocate, she was best positioned to provide the first presentation to the wider community for input and opinion-seeking regarding the consent process to be utilized at the community, high school and individual level.

While a more detailed definition and explanation of what was involved in gaining community consent is articulated in a previous paper by this group (see Zahradnik et al., 2007a), for the purpose of the present paper it is important to summarize how community input molded the nature of the final project. The KT component of this project has been ongoing, and effectively began during the principal investigator's (PI's) first formal meeting with the community-based collaborative and therapeutic team (Case Management) and the InterAgency (from here on in referred to as an advisory group), which jointly consist of representatives from the following service providers/institutions: Mental Health and Social Work Services, Native Alcohol and Drug Abuse Counselling Association (NADACA), the Health Centre, Home Care, Mi'kmaq Family and Children's Services, the Regional Hospital's Child and Adolescent Services, the RCMP, as well as three schools under the jurisdiction of the School Board.

The Canadian Institutes of Health Research has defined knowledge translation as follows:

Knowledge translation is the exchange, synthesis and ethically-sound application of knowledge within a complex system of interactions among researchers and users - to accelerate the capture of the benefits of research for Canadians through

\footnotetext{
3 We use this term instead of child maltreatment because we measured physical, sexual, and emotional abuse / witnessing violence, but not neglect.
} 
improved health, more effective services and products, and a strengthened health care system (CIHR, 2006).

This definition is particularly important in light of what has been referred to as the "two communities" problem (Caplan, 1979). The term was originally intended to describe how researchers and policy makers inhabit different worlds with different language and culture. However, the term is equally applicable in this context, where the PI and university-based researchers and the community service providers came from "different worlds." Having the counsel and active support of a community-based advocate, the distance between these two worlds was bridged, given the advocate's personal and professional ties to the reserve on the one hand, and the knowledge and credentials of a Master's student of School Psychology on the other.

Issues around maltreatment and addictions were not new to the community advisory group to the research project, and their collective expertise on how these issues have been affecting their community guided the development of the study design (see below). Likewise, many agency representatives, although familiar with the term PTSD in passing, readily appreciated how many of the youth they were seeing were demonstrating behaviors that could be consistent with a presentation of PTSD (e.g., avoidance, volatile temper). However, although the term PTSD was initially used during the presentation to the advisory group, it was ultimately concluded that diagnostic labels would not be used. This conclusion came to pass based on a convergence of views between the community and the research team, since both groups had some concerns about the use of diagnostic labels within this research context. Thus, instead of measuring PTSD categorically (diagnosis is present or not present), the research team was able to choose from several selfreport measures for the intended age range that would measure PTSD symptoms on a continuum of severity (very low to very high). This solution left both partners with a sense of confidence in how the study design could maintain a harmonious balance between sensitivity to the community needs and preferences on the one hand and scientific rigor on the other.

The study design continued to evolve through further dialogue with the agency representatives whose community-based knowledge ensured that the study would focus on those issues most salient to the community. Particularly, one key change was to be made to the design of the study before the study was fully embraced by the community. Specifically, at the request of advisory board members, a measure of depression and a measure of resiliency were added in place of other questionnaires, with a concern to be able to understand when/how youth are able to right a negative developmental trajectory (for a rationale, see Zahradnik et al. 2007a). Furthermore, in subsequent meetings, many individuals were concerned that the questions being asked of the students (about exposure to sexual and physical abuse) might lead to elevated levels of distress, and possibly suicide. This concern was addressed in several ways. First, the PI reassured the concerned individuals that empirical evidence overwhelmingly suggests that answering questions about physical and sexual trauma, or writing about trauma in general, does not tend to lead to elevated levels of distress for most individuals (Carlson et al., 2003), and can actually be therapeutic (Pennebaker, 1997). Second, our community advocate was able to share her professional experience of working with abused youth on a daily basis as a high school counselor where daily functioning was maintained by youth. Third, since the information was to be collected anonymously by paper-and-pen self report measures, it was jointly decided that the measure of depression used should not include a question on suicide, since the team would be incapable of following-up on any students who self-identified as at an elevated risk for suicide (for complete details see Zahradnik et al., 2007a). And finally, the concerned individuals were reminded that Mental Health and Social Work Services (MH \& SWS) would be on call during the time of the data collection. There were, though, no reported incidences of students availing themselves of these services as a result of the study, although one youth discussed their maltreatment individually with the school counselor. That youth did not want to pursue individual counseling options at that time.

\section{Sharing of results}

Ultimately, it was collaboratively decided that the following topics would be investigated by way of self-report measures: exposure to violence (Childhood Experience of Violence Questionnaire, CEVQ; Walsh, MacMillan, Trocmé, Jamieson, \& Boyle, 2008), posttraumatic stress symptoms (Child PTSD Symptom Scale, CPSS; Foa, Johnson, \& Feeney, 2001), depressive symptoms (Center for Epidemiological Studies Depression Scale, CESD; Radloff, 1977), alcohol-related problems (Rutgers Alcohol Problem Index, RAPI; White \& Labouvie, 1989), and resiliency (Child and Youth Resilience Measure, CYRM; Ungar, et al., 2008). Given that some members of the community were concerned about how the research might be used, and how their community could benefit from the research, we jointly formulated a community dissemination plan. According to Hanson and Smiley (2006), a community dissemination (KT) plan should ensure that the research is returned to the community so as to guarantee that the community can benefit from the research. The community dissemination 
plan for the results involved four partially overlapping targeted audiences: the advisory group, the director of $\mathrm{MH}$ and SWS, the school staff (including administrators, teachers, and guidance counselors), and the students themselves. Each target audience received a presentation that was tailored to their specific needs.

For the advisory group, the full results of the study were presented at an Inter- Agency meeting, a forum for representatives of all community service providers to meet and discuss issues of relevance to the community. The presentation followed the format of an interactive science presentation for non-specialists. This presentation style allowed the PI to present the material in a manner that was consistent with how the study had initially been proposed to the advisory board. It also ensured that all questions from the advisory group were addressed and that the PI could receive feedback, particularly about what the advisory group wanted to do with the information collected through the project. Together, it was determined that community services providers who work with youth (and adults) might benefit from a series of training workshops that addressed issues around the screening/assessment and management of PTSD symptoms in their youth, as well as methods for promoting resiliency (see next section).

With respect to information collected on maltreatment, it was felt that the descriptive results would be most helpful if they were reported back to the social services director in a format that could be used to supplement this agency's funding applications. In other words, the advisory group felt that a document on rates of the studied variables (e.g., exposure to violence)reported by the school-attending youth - could be used to the community's benefit in terms of being readily available for use in their applications to funding agencies for increased funding to deal with these types of issues in their communities. To this end, this director, as the second target audience, received a technical report that provided the following information: descriptive information on alcohol, drug, and tobacco use; descriptive information about depression and PTSD symptoms; descriptive information on about the rates of both physical abuse and sexual abuse, including the perpetrators' gender and relation to the victim; as well as an analysis of the effect that various forms of abuse (physical, sexual, or combined abuse) had on rates of substance use and mental health ${ }^{4}$.

With respect to the schools where this study took place, the administrators believed that all school staff would benefit from hearing about the results. Therefore, the PI gave separate presentations at each school. These

\footnotetext{
4 To date this information has been used to compliment three distinct funding applications by the present mental health/social services director of this community.
}

presentations helped place some of the more problematic student behaviors (e.g., sudden angry outburst) into a greater context of distress for the teachers. It also resulted in the teachers unanimously accepting the research team's proposal of making use of class time to discuss the results of the study with the fourth target audience - the students themselves.

How to best address the student audience was determined in consultation with the guidance counselors and senior administrators of each school. Firstly, it was thought that since PTSD was not a well understood or discussed topic in the health curriculum, the students would be best served if the presentations focused less on the scientific results of the study, and more on what PTSD is, how to recognize each symptom cluster (i.e., re-experiencing, hyper-arousal, and avoidance/ numbing), and how to get help for PTSD within their community. Second, while the PI and university basedresearch team proposed the idea of giving talks to all students at each school (i.e., mandatory attendance), the principal of the larger school decided it would be best to post advertisements for interested students, while the guidance counselor of the smaller school hand-picked the students she believed to be struggling with issues relevant to PTSD. Presentations to the students occurred in small groups, typically no more than eight per group, and typically homogeneous with respect to gender. Presentations emphasized using community resources for help (e.g., guidance counselor, anonymous 24-hour national youth help phone etc.), that avoidance behaviors (e.g., coping by way of drugs and alcohol) are more likely to result in continued symptoms, and the benefit of positive coping styles (e.g., regular exercise, talking with friends). The student response to these presentations is documented below.

\section{Tangible benefits and documented results}

This section will outline the tangible benefits to the community that have occurred as a result of the study in terms of quantitative results. Student presentations have been an ongoing activity at both schools, and to date thirty six students have received presentations. For the first fifteen students, some basic pilot data was collected on how they experienced the presentation. Participants were asked to answer four questions on a 1-5 Likert-type scale $(1=$ not at all, $2=$ a little, $3=$ somewhat, $4=$ quite a bit, $5=$ quite a lot). Grouping students on whether or not they responded to each question with a score of 4 or more (quite a bit), $87 \%$ of students believed that the presentation improved their understanding of PTSD, while $80 \%$ felt that the content was personally meaningful. But while $67 \%$ felt like they were more likely to encourage someone close to them consult a health care provider 
after hearing the presentation, only $27 \%$ indicated they were more likely to see a health care provider themselves as a result of the presentation. Unfortunately, for this group of students, it could not be determined whether their reluctance to visit a health care professional was a result of their own adaptive functioning (or lack of personal relevance of the topic for them if they had not been exposed to violence or experienced PTS reactions themselves), external obstacles, or internal obstacles (e.g., lack of belief that someone can help). The PI attempted to address this question, and several others, in the next wave of presentations.

To get a better understanding of whether or not these presentations were objectively increasing students' knowledge of PTSD and how students were presently coping with their stress, a new set of questions were devised. Students were asked a total of five multiple choice and true false questions about PTSD (e.g., what are the three symptom clusters) both before and after the presentations. They were also asked two questions about contact with mental health/wellness workers (including guidance counselors, social workers, and other mental health professionals), one pre-presentation question relating to frequency of contact with mental health/ wellness workers within the last year $(1=$ never, $2=$ once, $3=2-6$ times, $4=$ once a month, and $5=$ at least three times a month), and one post-presentation question about intention to contact mental health/wellness workers as a function of the presentation $(1=$ not at all, $2=$ a little, $3=$ somewhat, 4 = quite a bit, 5 = quite a lot).

In a pre to post information session analysis, knowledge scores (out of 5) improved significantly as a function of exposure to the information session (pre $=$ 2.93 vs. post $=3.73 ; \mathrm{t}(14)=2.703, \mathrm{p}=.017$; two tailed test). Forty two percent of the youth indicated that they had no previous contact with mental health/wellness workers, but reasons were not given as to why (e.g., no personal need, or alternatively, encountering barriers to treatment seeking). Inversely, in our small sample of self- or school-selected students, over $50 \%$ of students reported having seen a mental health/wellness worker at least once. While $50 \%$ of the students that answered the question indicated that they were more likely (score of 4 or 5) to urge a friend or a family member to contact a wellness worker as a result of the presentation, only one student said he/she was more likely to seek help herself. From the qualitative data provided by the students on how they deal with such problems without contacting a mental health/wellness worker, three patterns emerged: 1) active coping by talking to family or friends about the problem, 2) coping by way of pro-social avoidance (e.g., playing sports or activities), and 3) coping by way of problematic avoidance: e.g., taking drugs/alcohol, spending more time alone (social withdrawal).
While the numbers are small, and while the questions were not designed to screen for a history of trauma or active PTSD symptoms, an overall pattern seemed to emerge. First, the students subjectively felt that the information presented to them was relevant. Second, there was an objective demonstration of an increase in knowledge about PTSD by the end of the presentation (albeit these are pilot results as no control group was included). Third, while students reported that as a result of the presentation they were more likely to urge a friend or family member to seek help for trauma-related problems, only one student indicated that she was likely to seek help for her own trauma related problems. Unfortunately, although students were provided with space to write out open ended responses to why they would not seek out help for their own concerns, they were generally not forthcoming, though a couple students claimed not to have any problems. Furthermore, the category of mental health/wellness worker queried about included both guidance counselors and community mental health services staff, which suggests that there may be a greater reluctance to discuss these issues with anyone beyond family/friends, and not just an issue of worrying about being seen at a place dedicated to mental health and wellness.

It is difficult to account for the seeming disconnect between the high perceived relevance of the presentations to students, and their lack of consultations with mental health/wellness professionals (or the lack of effect of the presentation on shifting this reluctance to consult). Hopefully, as community service providers become more knowledgeable in screening for and treating PTSD in youth, community professionals will be able to encourage students to explore consultation options if they are struggling with issues related to post-traumatic stress. The community may want to explore the possibility of youth focus groups to get a better understanding of the complicated dynamics that affect students' decision making process behind their reluctance to seek help from community service providers.

While it has been important to the community to increase youth awareness around trauma and PTSD, these presentations have coincided with an initiative to increase the service providers' capacity to competently and confidently screen for PTSD symptoms and manage them as well. To this end, the PI co-facilitated a workshop for the community health and addictions professionals, by bringing into the community a professional clinical psychologist. On the morning of the workshop, the PI presented the results of the study. This was done to contextualize the content of the day's proceedings for those individuals whose involvement/knowledge of the research was more remote. Overall, twenty four service providers (primarily comprised of social workers, 
addiction counselors, and school guidance counselors) with an average of ten years of professional experience, attended the workshop. Given that none of the service providers in attendance had a degree that would allow them to make a diagnosis, the workshop emphasized screening procedures for PTSD. The workshop was divided into two components, one content-based and the other practice-based. The content component covered such questions as "What is PTSD and why does it occur (e.g., risk factors)?", "What are its symptoms?", "What other complications often accompany PTSD (e.g., co-morbidity with depression or substance abuse)?", and "What screening tools are available and how are they used?" The practice component consisted of five vignettes that were crafted by the presenter with the assistance of a Mi'kmaq addictions counselor. Attendees broke into small groups, and the members of the small groups worked together to apply the content they had learned to the presenting cases in front of them in order to identify what PTSD symptoms were present, and what other factors might be involved (e.g., social support vs. being isolated).

Based on a survey administered before the workshop began, only $26 \%$ (six) of the service-providers present indicated that they regularly screened for PTSD. However, $50 \%$ (six) of those who completed a postworkshop question on likelihood to screen, and who previously indicated that they were not presently screening for PTSD, indicated that they were more likely to screen for PTSD (minimum score of 4) as a result of the presentation. This means that by the end of the presentation, $67 \%$ (12) of the group indicated a willingness to screen for PTSD. This is encouraging given that $100 \%$ of those in attendance at the beginning of the presentation indicated that PTSD was a concern in their community. As with the students, a simple five-item knowledge test was given before and after the presentation and workshop. After removing from the analysis the data of the 5 individuals who had to leave the workshop early (where no post-session data was available), of the 19 participants who remained, even after counting blank answers as incorrect, there was a significant increase in knowledge from the prepresentation score out of five $(\mathrm{M}=3.26)$ compared to their post-presentation score $(\mathrm{M}=4.26)(\mathrm{t}(18)=3.082$, $\mathrm{p}=.006)$. Furthermore, a per item analysis (McNemar non-parametric Chi-square test) showed that group knowledge acquisition occurred for the following three items as a result of the presentation: question 1 showed increased knowledge that PTSD is an anxiety disorder ( $p$ $=.008$ ); question 2 increased knowledge about nature of the three PTSD symptom clusters $(\mathrm{p}=.016)$; and question 4 increased knowledge about the types of events that can cause PTSD $(\mathrm{p}=.031)$ (see Table 1$)$. There was no significant knowledge gain for questions $3 \& 5$ due to a ceiling effect, as most of the respondents provided the correct answer at baseline (i.e., pre-presentation).

With respect to whether or not the presentation influenced peoples attitude about whether or not they intend to screen for PTSD in the future, the correlation between responses to the item measuring "intent to screen" and the item measuring "confidence in being able to do so" was extremely high $(\mathrm{r}=.93, \mathrm{p}<.001)$. This high correlation suggests that self-efficacy is associated with behavioral intentions to change current practice. Anecdotally, those individuals who reported less of an intention to screen and less confidence in their ability to do so stated in writing that they felt more of this type of training was needed. The above information suggests that it is important that if session attendees are to make changes to their current practice, they need to leave the workshop with a high sense of self-efficacy about implementing a screening process in their practice.

Subsequent to PTSD symptom screening workshop, the PI arranged for a two day workshop on treating PTSD in youth. The material covered came from an interactive web-based teaching tool on trauma-focused cognitive behaviour therapy (TF-CBT) for youth (National Crimes Victim \& Treatment Centre, 2007; free training available on-line through the University of South Carolina at: http://

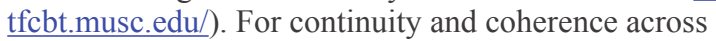
KT initiatives, the same clinical psychologist who lead the assessment workshop also facilitated the treatment workshop. Attendees were the project's communitychampion, another guidance counselor, a psychologist from a nearby Mi'kmaq community, the mental health director of this community and selected staff, as well as one representative from NADACA for a total of 10 . The purpose of the workshop was to introduce and familiarize the attendees with Trauma-Focused CognitiveBehavioural Therapy (TF-CBT; Cohen, Mannarino, \& Deblinger, 2006), and to stimulate the desire for further and more intense training in this therapeutic modality. The facilitating psychologist's role was to guide the group through the modules, while simultaneously encouraging discussions about the cross-cultural applications of the content. Attendees were given printed scripts for each module in advance, which included step-by-step instructions for each intervention. With the aid of a projector and internet connection, the facilitating psychologist was able to cover 5 modules each day, responding to questions and concerns as they arose.

The TF-CBT Web course comes with its own standardized pre and post module knowledge tests, allowing for an objective indicator of knowledge acquisition. Table 2 gives information on the group's prepost scores for each module with significant knowledge acquisition occurring in 3 of 9 modules (test information 
was not available for module 10). Specifically, the group showed knowledge acquisition in modules 1,8 , and 9: psychoeducation, cognitive processing of the trauma narrative, and behavioural management strategies. Furthermore, given the high pretest score (3.2 out of 4) for module 3 (relaxation training), a result comparable to that reported by the TF-CBT Web developers, it is likely that a ceiling effect limited the potential for knowledge acquisition in this module (National Crimes Victim \& Treatment Centre, 2007). Due to missing data — not all attendees were present for all modules and no data could be collected for module 10 (see Table 2) - a total score consisting of the sum of all modules could not be calculated. However, for the group as a whole, based on the modules that were completed, a paired sample t-test revealed a significant learning differential of 5.3 points, $\mathrm{t}(9)=4.19, \mathrm{p}<0.01$. Taken as a whole these results suggest that the small group of attendees left with a better understanding of TF-CBT.

The last workshop that was arranged for this community was a workshop on resilience by a national expert in the field. Current models of resilience depart from earlier conceptions that strictly emphasized individual factors (Anthony, 1987; Kaplan, 1999). Contemporary models are now shifting towards ecological interpretations (Lerner \& Benson, 2003; Ungar, 2001). More recently, resilience has been described as both an outcome of interactions between individuals and their environments (e.g., abusive home life; positive school life), and the processes (e.g., engagement with more positive adult role-models) which contribute to these outcomes (Ungar et al., 2007). Workshop attendees consisted of representatives from community agencies whose mandate involved youth (e.g., schools, MH \& SWS, RCMP). The workshop commenced with a presentation by the PI on recent findings from the community that involved resilience. Specifically, the attendees learned that resilience moderated (buffered) the impact of exposure to violence on PTSD reexperiencing symptoms (symptoms like intrusive memories and nightmares) in community youth (see Zahradnik, et al., in press). In other words, when community youth were exposed to high levels of violence, youth high in resilience experienced less PTSD reexperiencing symptoms than youth low in resilience. The workshop facilitator spent the rest of the morning discussing the construct of resilience in greater detail while the afternoon focused on selecting cases from the community that the service providers found challenging. Although no outcome data is available to index knowledge enhancement for this endeavor, a future collaborative partnership between the workshop leader and the community was discussed.

With the success of the PTSD symptom screening workshop, the TF-CBT Web workshop, the resilience workshop, the student presentations, and the progression towards addressing the reason why some students seem reluctant to consult with a guidance counselor or social worker, there is growing evidence that, as a function of our collaborative research partnership, the community is slowly becoming better equipped to deal with PTSD and its associated complications.

\section{Future directions and lessons learned}

Based on an interview with the mental health director - who has acted as a key informant (Tremblay, $1957)^{5}$ with respect to issues pertaining to mental health and wellness in the community - there are still challenges to overcome. First, screening for PTSD symptoms has begun; however, there is a reluctance to formalize such screening by way of standardized tools. Reportedly, this is due to the fact that the broader networks of mental health service providers who work with the various Mi'kmaq communities in this region prefer to maintain an informal atmosphere with their clients. Another possible method by which to ensure consistency of screening approaches would be to organize occasional PTSD-symptom-screening-booster-sessions. Further to this issue is the community-wide need for more training in the screening and treatment of anxiety disorders in general. This echoes some of the feedback from the screening workshop, in which a few individuals desired a greater understanding of differential diagnosis. Although the research has increased the community's awareness and knowledge of PTSD, it has simultaneously revealed another area in which the community service providers have requested more training. Furthermore, with respect to the TF-CBT Web workshop, published work that examines how Aboriginal clients respond to treatment modalities like CBT is only beginning to emerge. There is some evidence that non-acculturated Aboriginal clients (i.e., stronger identification with their own culture) may not agree with the rationale of how CBT works and by extension certain activities like linking thoughts to feelings, but do appreciate CBT's use of active and present focused interventions (see Jackson, Schmutzer, Wenzel, \& Tyler, 2006). A great deal of the workshop was spent on discussing these very issues with no firm conclusions being reached. The choice to offer this community a best-practice model of treatment (Cohen \&

\footnotetext{
5 The term key informant is used in the sense first employed by Tremblay (1957, p. 689) to designate an individual who provides information for "the study of specific aspects of a cultural setting..." by individuals with specialized information on a specific topic "... rather than the cultural whole usually detailed in ethnographies."
} 


\section{Knowledge Translation in a Community-Based Study}

Mannarino, 2008) was made with the understanding that more research needs to examine whether these non-Aboriginal best-practice models of treatment apply equally well to Aboriginal communities (including both acculturated and non-acculturated individuals). It remains a question for future collaborative partnerships between researchers and Aboriginal communities to determine which aspects of CBT should be modified so as to increase cultural acceptability of the intervention without decreasing its overall effectiveness.

Another issue that has arisen is how to keep the broader community of service providers actively discussing and learning about issues around interpersonal trauma and PTSD. Attempts at inviting individuals to join a list serve did not meet with much success, despite the fluency with on-line communication and computing resources. This served as a reminder to the PI that the community service providers are not only overworked with their case loads, but are constantly attending workshops and training put on by other health focused organizations. The questions of whether or not this community makes use of the web-based tools in the same manner as others, and how to make these list-serves more relevant to the community service providers still need to be addressed.

Finally, there still exists a relatively entrenched culture of silence around sexual assault and healthy sexuality for youth. The mental health director speculates that more education around these issues is a necessary step towards progress, and raised the issue of how lateral violence (LV) may preclude open discussion of assaults in close relationships. Lateral violence is a term more widely cited in the nursing literature (e.g., Stanley, Martin, Michel, Welton, \& Nemeth, 2007), but its origin can be traced back to Freire's (1971) oppressed group model and description of horizontal violence. Some examples of LV include: non-verbal innuendo, verbal affront, undermining activities, infighting, scapegoating, backstabbing, failure to respect privacy, and broken confidences (Griffin, 2004). If this dynamic exists between peers, it would likely engender a reluctance to trust, a reluctance that may also manifest itself with respect to the family and community more broadly when acts of physical or sexual violence occur (Thibodeau \& Peigan, 2008).

The community maintains a concern for its youth. Importantly, many of the community service providers now have a much clearer understanding of the specific problems their youth are dealing with, and how these problems often co-occur in a meaningful way. Our collaborative work has helped the community identify ways in which they can begin to respond to some of these problems (e.g., training in the identification and management of PTSD symptoms). Furthermore, the community professional services are now directly addressing early intervention for sexual assault and reviewing prevention strategies. We believe that our partnership with this community has the potential to lead to further collaborative integrative KT work. We also hope that it will provide some guidance to researchers and Aboriginal communities who, with the unified purpose of supporting the recovery and resilience of youth in their communities, wish to embark upon a reciprocal journey towards knowledge discovery, exchange, and application.

\section{References}

American Psychiatric Association. (1994). Diagnositic and statistical manual of mental disorders (4th ed.). Washington, DC: Author.

Anthony, E. J. (1987). Risk, vulnerability, and resilience: An overview. In E. J. Anthony and B. J. Cohler (Eds.), The invulnerable child (pp. 3-48). New York: Guilford Press.

Armitage A. (1995). Comparing the policy of Aboriginal assimilation: Australia, Canada, and New Zealand. Vancouver, Canada: University of British Columbia Press.

Bennett, M., \& Blackstock, C. (2002). A literature review and annotated bibliography focusing on aspects of aboriginal child welfare in Canada. Ottawa, Canada: First Nations Child and Family Caring Society of Canada.

Brewin, C. R., Andrews, B., \& Valentine, J. D. (2000). Metaanalysis of risk factors for posttraumatic stress disorder in trauma exposed adults. Journal of Consulting and Clinical Psychology, 68, 748-66.

Caplan, N. (1979). The two communities theory and knowledge utilization. American Behavioural Scientist, 22, 459-70.

Canadian Institutes of Health Research (CIHR) (2006). Moving Population and Public Health Knowledge into Action: A Casebook of knowledge translation stories. Ottawa, ON: Canadian Institutes of Health Research (CIHR).

Carlson, E. B., Newman, E., Daniels, J. W., Armstrong, J., Roth, D., \& Lowenstein, R. (2003). Distress in response to and perceived usefulness of trauma research interviews. Journal of Trauma and Dissociation, 4, 131-142.

Chilcoat, H. D., \& Breslau, N. (1998). Posttraumatic stress disorder and drug disorders: Testing causal pathways. Archives of General Psychiatry, 55, 913-917.

CIHR (2008a). The KT Portfolio at CIHR. Retrieved, February 1st, 2008. http://www.cihr-irsc.gc.ca/e/29418.html.

CIHR (2008b). Knowledge Translation Overview. Retrieved February 1st, 2008. http://www.cihr-irsc.gc.ca/e/7518.html.

Cohen, J. A., \& Mannarino, A. P. (2008). Disseminating and implementing trauma-focused CBT in community settings. Trauma, Violence, and Abuse, 9, 214-226.

Cohen, J.A., Mannarino, A. P., \& Deblinger, E. (2006). Treating Trauma and Traumatic Grief in Children and Adolescents. New York: Guilford Publications, Inc. 
Comeau, N. M., Stewart, S. H., Mushquash, C., Wojcik, Bartlett, C., Marshall M., et al. (2005). Community collaboration in developing a culturally relevant alcohol abuse early intervention program for First Nation youth. Ontario Association of Children's Aid Societies Journal, 49, 35-41.

De Bellis, M.D. (2002). Developmental traumatology: A contributory mechanism for alcohol and substance use disorders. Psychoneuroendorcrinology, 27, 155-170.

First Nations Child and Family Caring Society of Canada. (2005). Wen:De - We are Coming to the Light of Day. Ottawa, ON: FNCandFCS.

Foa, E.B., Johnson, K.M. \& Feeny, N.C. (2001). The child PTSD symptom scale: A preliminary examination of its psychometric properties. Journal of Clinical Child Psychology, 30, 376-384.

Freire, P. (1971). Pedagogy of the oppressed. New York: Herder \& Herder.

Gagne, M. (1998). The role of dependency and colonialism in generating trauma in First Nations citizens. In Y. Danieli (Ed.), International handbook of multigenerational legacies of trauma (pp. 355-372). New York: Plenum Press.

Grant, A. (1996). No End of Grief: Indian Residential Schools in Canada. Winnipeg, MA: Pemmican.

Griffin, M. (2004). Teaching cognitive rehearsal as a shield for lateral violence: An intervention for newly licensed nurses. Journal of Continuing Education in Nursing, 35, 1-7.

Hanson, G. \& Smiley, J. (2006). Sharing what we know about living a good life - Knowledge translation summit report and toolkit. Indigenous Peoples' Health Research Centre. http://www.iphrc.ca/resources/iphrc-research-documentsand-reports.htm.

Indian and Northern Affairs Canada (1996). Report of the Royal Commission on Aboriginal Peoples Vol. 1, Part II, Chapter 10 - Residential Schools. Canada: http://www.ainc-inac. gc.ca/ch/rcap/sg/sgm10 e.html.

Jackson, L., Schmutzer, P., Wenzel, A., \& Tyler, J. (2006). Applicability of cognitive-behavior therapy with American Indian individuals. Psychotherapy: Theory, Research, Practice, Training, 43, 506-517.

Jacobsen, L. K., Southwick, S. M., \& Kosten, T. R. (2001) Substance use disorders in patients with posttraumatic stress disorder: A review of the literature. American Journal of Psychiatry, 158, 1184-1190.

Kaplan, H. B. (1999). Toward an understanding of resilience: A critical review of definitions and models. In M. D. Glantz and J. L. Johnson (Eds.), Resilience and development: Positive life adaptations (pp. 17-84). New York: Kluwer/ Plenum.

Kilpatrick, D.G., Ruggiero, K.J., Acierno, R., Saunders, B., Resnick, H.S., \& Best, C.L. (2003). Violence and risk of PTSD, major depression, substance abuse/dependence, and comorbidity: Results from the National Survey of Adolescents. Journal of Consulting and Clinical Psychology, 71, 692-700.
Kirmayer, L. J., Brass, G. M., \& Tait, C. L. (2000). The mental health of Aboriginal peoples: Transformations of identity and community. Canadian Journal of Psychiatry, 45, 607-616.

Knockwood, I. (1992). Out of the depths: The experiences of Mi' kmaw Children at the Indian residential school at Shubenacadie, Nova Scotia. Lockeport, NS: Roseway Publishing.

Lerner, R. M., \& Benson, P. L. (Eds.). (2003). Development assets and asset-building communities: Implications for research, policy, and practice. New York: Kluwer Academic/Plenum.

Miller, J.R. (1996). Shingwauk's vision: A history of native residential schools. Toronto: University of Toronto Press.

Mushquash, C. J., Comeau, M. N., \& Stewart, S. H. (2007). An alcohol abuse early intervention approach with Mi'kmaq adolescents. First Peoples Child and Family Review, 3, 17-26.

National Crime Victims Research and Treatment Center. (2007). TF-CBTWeb: First Year Report. Charleston, SC: Author.

Pennebaker, J.W. (1997). Opening Up: The Healing Power of Expressing Emotion. New York: Guilford Press.

Quinn, A. (2007). Reflections on intergenerational trauma: Healing as a critical intervention. First Peoples Child and Family Review, 3, 72-82.

Radloff, L. S. (1977). The CES-D scale: A self-report depression scale for research in the general population. Applied Psychological Measurement, 1, 385-401.

Stanley, K. M., Martin, M. M., Nemeth, L. S., Michel, Y., \& Weiten, J. M. (2007). Examining lateral violence in the nursing workforce. Issues in Mental Health Nursing, 28, 1247-1265.

Stewart, S. H. (1996). Alcohol abuse in individuals exposed to trauma: A critical review. Psychological Bulletin, 120, 83-112.

Stewart, S. H. \& Conrod, P. J. (2008). Anxiety disorder and substance use disorder co-morbidity: Common themes and future directions. In S. H. Stewart and P. J. Conrod's (Eds.), Anxiety and Substance Use Disorder: The Vicious Cycle of Comorbidity (p. 239-257). New York: Springer.

Thibodeau, S. \& Peigan, F. N. (2008). Loss of trust among First Nations people: Implications when implementing child protection treatment initiatives. First Peoples Child and Family Review, 3, 50-58.

Thomas, W. \& Bellefeuille, G. (2006). An evidence-based formative evaluation of a cross-cultural Aboriginal program in Canada. Australian e-journal for the Advancement of Mental Health (AeJAMH), 5(3): Available online at http:// www.auseinet.com/journal/vol5iss3/thomas.pdf.

Tremblay, M-A. (1957). The key informant technique: A nonethnographic application. American Anthropologist, 59, 688-701.

Ungar, M. (2001). The social construction of resilience among "problem" youth in out-of-home placement: A study of 


\section{Knowledge Translation in a Community-Based Study}

health-enhancing deviance. Child and Youth Care Forum, 50, 137-154.

Ungar, M., Brown, M., Liebenberg, L., Othman, R., Kwong, W. M., Armstrong, M., et al., (2007). Unique pathways to resilience across cultures. Adolescence, 42, 287-310.

Ungar, M., Liebenberg, L., Boothroyd, R., Kwong, W. M., Lee, T. Y., Leblanc, J., et al. (2008). The study of youth resilience across cultures: lessons from a pilot study of measurement development. Research in Human Development, 5, 166-180.

Walsh, C. A., MacMillan, H. L., Trocmé, N., Jamieson, E., \& Boyle, M. H. (2008). Measurement of victimization in adolescence: Development and validation of the Childhood Experiences of Violence Questionnaire. Child Abuse and Neglect, 32, 1037-1057.

Wekerle, C., \& Wall, A.-M. (2002). Introduction: The overlap between relationship violence and substance abuse. In C. Wekerle and A.M. Wall (Eds.), The violence and addiction equation: Theoretical and clinical issues in substance abuse and relationship violence (pp. 1-21). New York: Brunner Routledge.

Wesley-Esquimaux, C. C., \& Smolewski, M. (2004). Historic Trauma and Aboriginal Healing. Ottawa: Aboriginal Healing Foundation.

White, H. R., \& Labouvie, E. W. (1989). Towards the assessment of adolescent problem drinking. Journal of Studies on Alcohol, 50, 30-37.

Zahradnik, M., Stevens, D., Stewart, H. S., Comeau, M. N., Mushquash, C. J., \& Wekerle, C. (2007a). Building a collaborative understanding of pathways to adolescent alcohol misuse in a Mi'kmaq community: A process paper. First Peoples Child and Family Review, 3, 27-36.

Zahradnik, M., Stewart, S. H., O'Connor, R. M., Stevens, D., Ungar, M., \& Wekerle, C. (in press). Resilience moderates the relationship between exposure to violence and posttraumatic reexperiencing in Mi'kmaq youth. International Journal of Mental Health and Addiction. doi 10.1007/s11469-009-9228-y.

Zahradnik, M., Stewart, S. H., Stevens, D. S., Wekerle, C., Comeau, N. M., \& Mushquash, C. (2007b). The mediating role of post-traumatic stress symptoms between exposure to violence and substance misuse in a sample of school attending Mi'kmaq adolescents. Abstract published in Canadian Psychology, 48, 127.
Table 1. PTSD Screening Workshop Knowledge Test Scores at Pre-test and Post-test

\begin{tabular}{|c|c|c|}
\hline \multicolumn{3}{|c|}{ Question 1** } \\
\hline & \multicolumn{2}{|c|}{ Post-test } \\
\hline Pre-test & Incorrect & Correct \\
\hline Incorrect & 0 & 8 \\
\hline Correct & 0 & 10 \\
\hline \multicolumn{3}{|c|}{ Question 2* } \\
\hline & \multicolumn{2}{|c|}{ Post-test } \\
\hline Pre-test & Incorrect & Correct \\
\hline Incorrect & 5 & 7 \\
\hline Correct & 0 & 6 \\
\hline \multicolumn{3}{|c|}{ Question 3} \\
\hline & \multicolumn{2}{|c|}{ Post-test } \\
\hline Pre-test & Incorrect & Correct \\
\hline Incorrect & 1 & 1 \\
\hline Correct & 0 & 15 \\
\hline \multicolumn{3}{|c|}{ Question 4* } \\
\hline & \multicolumn{2}{|c|}{ Post-test } \\
\hline Pre-test & Incorrect & Correct \\
\hline Incorrect & 1 & 6 \\
\hline Correct & 1 & 11 \\
\hline \multicolumn{3}{|c|}{ Question 5} \\
\hline & \multicolumn{2}{|c|}{ Post-test } \\
\hline Pre-test & Incorrect & Correct \\
\hline Incorrect & 0 & 2 \\
\hline Correct & 0 & 16 \\
\hline
\end{tabular}

Notes: Questions 1, 2, and 4 are in bold because they are significant according to a McNemar test where * $=$ significant at $.05, * *=$ significant at .01 . Values in the Correct (row)-Correct (column) areas represent respondent responses that were correct at both pre-test and post-test, while values in the Incorrect (row)-Correct (column) areas represent respondent responses that were incorrect at pre-test but correct at post-test. 


\section{First Peoples Child \& Family Review, Volume 4, Number 2, 2009}

Table 2. TF-CBT Web Workshop Knowledge Test scores at Pre-test and Post-test

\begin{tabular}{|c|c|c|c|}
\hline Module & $\begin{array}{l}\text { Pre-test } M \\
(S D)\end{array}$ & $\begin{array}{l}\text { Post-test } M \\
(S D)\end{array}$ & Difference \\
\hline 1: Psychoeducation & $1.40(0.70)$ & $2.80(1.4)$ & +1.4 \\
\hline $\begin{array}{l}\mathrm{N}=10 \\
2: \text { Controlled Breathing }\end{array}$ & $2.40(0.52)$ & $2.90(1.0)$ & $\begin{array}{l}t=2.80 \\
+0.50\end{array}$ \\
\hline $\begin{array}{l}\mathrm{N}=10 \\
\text { 3: Relaxation }\end{array}$ & $3.20(1.03)$ & $3.70(0.67)$ & +0.50 \\
\hline $\begin{array}{l}\mathrm{N}=10 \\
\text { 4: Thought Stopping }\end{array}$ & $1.67(0.87)$ & $1.44(0.88)$ & -0.23 \\
\hline $\begin{array}{l}\mathrm{N}=9 \\
\text { 5: Affect Expression }\end{array}$ & $2.20(1.03)$ & $2.60(0.97)$ & +0.40 \\
\hline $\begin{array}{l}\mathrm{N}=10 \\
6: \text { Cognitive Coping }\end{array}$ & $2.50(0.97)$ & $2.80(0.79)$ & +0.30 \\
\hline $\begin{array}{l}\mathrm{N}=10 \\
\text { 7: Trauma Narrative }\end{array}$ & $2.00(0.63)$ & $2.67(0.82)$ & +0.67 \\
\hline $\begin{array}{l}\mathrm{N}=6 \\
\text { 8: Cognitive Processing }\end{array}$ & $1.00(1.32)$ & $2.44(0.88)$ & +1.44 \\
\hline $\begin{array}{l}N=9 \\
9: \text { Behavioural Management }\end{array}$ & $2.00(0.53)$ & $2.88(0.83)$ & $\begin{array}{l}t=3.50 p<.01 \\
+0.88\end{array}$ \\
\hline $\mathrm{N}=8$ & & & $t=3.90 p<.01$ \\
\hline 10: Parent-Child Sessions & - & - & - \\
\hline
\end{tabular}

Notes: Modules in bold showed significant knowledge improvement. $\mathrm{M}=$ mean, $\mathrm{SD}=$ standard deviation. 